\title{
EDITORIAL
}

\section{Alchemy and psychology}

\section{ALCHEMY AND PSYCHOLOGY: ALCHEMIZING YOUR CHALLENGING EXPERIENCES}

Regular readers of Palliative \& Supportive Care will not be surprised to hear that I often find inspiration for editorials and essays for the journal from a variety of perhaps unusual sources: the astrophysicist Carl Sagan, the lyrics of a song by Sting, the Book of Job, the philosophy of Jacques Derrida, and the fog in Venice. But like many of you, my interests are thankfully constantly growing, changing, and expanding, in sometimes unexpected directions (not to worry, nothing illegal). Music, for instance, is a great joy of my life, as I assume it holds similar pleasures for many of you. Over the past two years now, I have developed a great interest and delight in the music of a British rock group Coldplay and their lead singer/songwriter Chris Martin. I love the music and have favorite songs from most of their albums, including "Ghost Stories," "Mylo Xyloto," "Viva la Vida," and "Head Full of Dreams" (in case any of you want to check out the music). I love dancing to one of their songs, "Adventure of a Lifetime," during my meaning-centered psychotherapy workshops, which I've conducted all over the world. I've also developed a great fondness for the talents, wit, and charm of Chris Martin, the lead singer, songwriter, and spokesman for the group. He became more well-known beyond the world of music after his marriage to Oscar-winning actress Gwyneth Paltrow. On a personal level, my son Sam is the spitting image of Chris Martin, so there's a great deal of "transference" at play when I watch Chris Martin or listen to his interviews. As some of you may know, Martin and Paltrow had a "conscious uncoupling" two years ago (what we usually call a marital separation and divorce). What I learned from watching interviews with him over the years after this marital and family breakup is that he had become quite depressed and saw the experience as traumatic, deeply damaging, and negative. His sense of self, his identity, and the meaning in his life were dramatically affected by what he saw as a tragedy for his life.

In a BBC Radio 1 interview on April 28, 2014, he was discussing the genesis of his then-new album
"Ghost Stories." He described the idea of the album as "how do you let negative things that happen to you affect your present and your future-do you let them drag you down, ruin your life?" Later in the interview, he described how he dealt with the blow that life had dealt him (the dissolution of his seven-year marriage and family): "I sought the help of a very wise Sufi teacher, who advised me to sit with my negative experience and all I'd been through, and he gave me the tools to allow me to "alchemize" my emotions and experiences and to take them and help them fit together-making my life something stronger, making me stronger." Alchemizing negative experiences and emotions to create something stronger, a stronger self! I had never heard the term "alchemizing" used in connection with emotions or experiences, but it caught my attention. There was something about the term and the process of alchemy that resonated within me, and it sat with me for almost a year, until I realized that it was in fact a main element in meaning-centered psychotherapy-attitudinal sources of meaning-choosing your attitude toward suffering and choosing how to respond to any event, particularly an event that has caused suffering, and choosing to create something transcendent, greater, stronger, defining, inspiring, and powerfully meaningful: creating the who you are in life by choosing how to respond to both joyful and tragic events.

\section{ALCHEMY AND PSYCHOLOGY}

There was much more to alchemy and its relationship to human psychology than I realized at the time I was struck by the idea of "alchemizing" one's emotions and experiences. For instance, there was Carl Jung! Psychology and Alchemy (Jung, 1968) is Volume 12 of The Collected Works of C.G. Jung. The book is a study of the analogies between alchemy, psychological symbolism, and aspects of religion, human spirituality, and transcendence. Alchemy is central to Jung's concept of the collective unconscious, his ideas about the aims and processes of psychotherapy, and the analytic process in general. Jung highlights the importance of alchemy in 
relating to the transcendent nature of the human psyche.

At its essence, alchemy is a power or process that changes or "transforms" something in a mysterious or profound way. While many cultures developed a philosophy and proto-scientific art of alchemy, medieval alchemy was a speculative science and philosophy aimed at achieving the transmutation of base, vulgar, impure, damaged base metals (like lead) into a higher and purer form: gold. During the Middle Ages and Renaissance times, alchemy spread throughout the Western world and was further developed by Kabbalists, Rosicrucians, astrologers, and other occultists. It functioned on two levels: the mundane and the spiritual. On the mundane level, alchemists sought to find a physical process to convert base metals into gold. On the spiritual level, alchemists worked to purify themselves by eliminating the "base" material of the self and achieving the "gold" of enlightenment.

The fact is that dozens of forms of "new age" psychotherapies and spiritual therapies have emerged during recent years that utilize the metaphors of alchemy and actually prescribe processes and practices, named after the processes of alchemy, in order to deal with life's challenges and emotional difficulties.

\section{ALCHEMY, EXISTENTIAL ISSUES, AND PALLIATIVE CARE}

In thinking about alchemy or the idea of "alchemizing" experiences and emotions in the palliative care setting, I came back to the main concepts of growth (posttraumatic growth): benefit-finding, meaningmaking, attitude, transcendence, and choosing one's attitude and response to suffering, limitations, uncertainty, and the finiteness of life. I pondered our attitudes and the way in which we choose to think about circumstances where we have lost all control, all our ability to influence an outcome as the last vestige of human freedom. That if we must die, we can choose to transform the experience into the ultimate human experience, which is to bear witness to human suffering and the defining element of humanity, that is, to realize that we exist and that we can cease to exist. To choose to believe that death is something uniquely human, to be able to contemplate and experience it as what completes a "human" life. It's up to us to choose how we die, and how we teach others to die-and that even in death there can be beauty and sacredness.

\section{REFERENCE}

Jung, C.G. (1968). Psychology and Alchemy: Collected Works of C.G. Jung, Vol. 12. Princeton, NJ, Princeton University Press.

WILLIAM BREITBART, M.D. Editor-in-Chief, Palliative \& Supportive Care Chairman, Jimmie C. Holland Chair in Psychiatric Oncology Chief, Psychiatry Service, Department of Psychiatry \& Behavioral Sciences Memorial Sloan Kettering Cancer Center 641 Lexington Avenue, 7th Floor New York, New York 10022, USA

E-mail: Breitbaw@mskcc.org 